\title{
A Simple Approach for Minimally Invasive Combined Aortic and Mitral Valve Surgery
}

\author{
Hesham Alkady ${ }^{1}$ Sobhy Abouramadan ${ }^{1}$ \\ ${ }^{1}$ Department of Cardiothoracic Surgery, Cairo University, Cairo, Egypt \\ Thorac Cardiovasc Surg 2022;70:120-125.
}

Address for correspondence Hesham Alkady, MD, Kasralaini str., Almanial, Cairo 5878, Egypt (e-mail: heshamalqady@cu.edu.eg).

\begin{abstract}
\section{Keywords}

- heart valve surgery

- minimally invasive surgery

- ministernotomy

- sternum

- mitral valve surgery

- aorta/aortic

Background There is now extension of minimally invasive techniques to involve concomitantly aortic and mitral valves through a single small incision. We share our experience in such surgeries through upper partial sternotomy with approaching the mitral valve through the dome of the left atrium.

Methods Two matched groups of cases receiving concomitant aortic and mitral valve surgeries are compared regarding the surgical outcomes: the minimally invasive group (group A) including 72 patients and the conventional group (group B) including 78 patients. Results The mean age was $52 \pm 8$ years in group $A$ and $53 \pm 7$ years in group $B$. Males represented (42\%) in group $A$ and $(49 \%)$ in group $B$. The mean mechanical ventilation time was significantly shorter in group $A(4.3 \pm 1.2$ hours) than in group $B(6.1 \pm 0.8$ hours) with a $p$-value of 0.001 . In addition, the amount of chest tube drainage and the need for blood transfusion units were significantly less in group A $\left(250 \pm 160 \mathrm{~cm}^{3}\right.$ and $1.3 \pm 0.8$ units, respectively) when compared with group $B\left(320 \pm 180 \mathrm{~cm}^{3}\right.$ and $1.8 \pm 0.9$ units, respectively) with $p$-values of 0.013 and 0.005 , respectively. Over a follow-up period of $3.2 \pm 1.1$ years, one mortality occurred in each group with no significant difference ( $p$-value $=0.512$ ). Conclusion Combined aortic and mitral valve surgery through upper partial sternotomy with approaching the mitral valve through the dome of the left atrium is safe and effective with the advantages of less postoperative blood loss, need for blood transfusion, and mechanical ventilation time compared with conventional aortic and mitral valve surgery.
\end{abstract}

\section{Introduction}

With the worldwide awareness and practice of isolated minimally invasive mitral and aortic valve surgeries, there is now extension of these techniques to involve concomitantly both valves through a single small incision minimizing the surgical trauma without compromising the final outcome. ${ }^{1}$ Studies reporting minimally invasive combined aortic and mitral valve surgeries through different approaches are increasing recently. ${ }^{2,3}$ In this study, we share our experience with minimally invasive combined aortic and mitral valve surgery through upper partial sternotomy, approaching the mitral valve through the dome of the left atrium.

\section{Patients and Methods}

\section{Study Design and Population}

In the period between September 2017 and June 2021, we performed a total of 258 cases of concomitant aortic and mitral valve surgeries, of which 72 cases were done received

July 25,2021

accepted after revision

September 1, 2021

published online

December 28, 2021
DOI https://doi.org/ 10.1055/s-0041-1740240. ISSN 0171-6425.

\footnotetext{
(C) 2021. The Author(s).

This is an open access article published by Thieme under the terms of the Creative Commons Attribution-NonDerivative-NonCommercial-License, permitting copying and reproduction so long as the original work is given appropriate credit. Contents may not be used for commercial purposes, or adapted, remixed, transformed or built upon. (https://creativecommons.org/ licenses/by-nc-nd/4.0/) Georg Thieme Verlag KG, Rüdigerstraße 14, 70469 Stuttgart, Germany
} 
Table 1 Preoperative patient characteristics in both groups

\begin{tabular}{|c|c|c|c|}
\hline Preoperative data & Group A (72) & Group B (78) & $p$-Value \\
\hline Age (years) & $52 \pm 8$ & $53 \pm 7$ & 0.415 \\
\hline $\begin{array}{l}\text { Sex } \\
\text { Male } \\
\text { Female }\end{array}$ & $\begin{array}{l}30(42 \%) \\
42(58 \%)\end{array}$ & $\begin{array}{l}38(49 \%) \\
40(51 \%)\end{array}$ & 0.482 \\
\hline Body mass index $\left(\mathrm{kg} / \mathrm{m}^{2}\right)$ & $27.5 \pm 2.8$ & $28.0 \pm 2.3$ & 0.232 \\
\hline $\begin{array}{l}\text { NYHA class } \\
\text { Class II } \\
\text { Class III }\end{array}$ & $\begin{array}{l}23(32 \%) \\
49(68 \%)\end{array}$ & $\begin{array}{l}19(24 \%) \\
59(76 \%)\end{array}$ & $\begin{array}{l}0.394 \\
0.302\end{array}$ \\
\hline $\begin{array}{l}\text { Valve pathology } \\
\text { Rheumatic } \\
\text { Degenerative }\end{array}$ & $\begin{array}{l}68(94 \%) \\
4(6 \%)\end{array}$ & $\begin{array}{l}70(90 \%) \\
8(10 \%)\end{array}$ & 0.447 \\
\hline Diabetes mellitus & $8(11 \%)$ & $10(13 \%)$ & 0.943 \\
\hline Atrial fibrillation & $14(19 \%)$ & $21(27 \%)$ & 0.374 \\
\hline Renal impairment & $4(5 \%)$ & $3(4 \%)$ & 0.913 \\
\hline Previous cerebrovascular stroke & $6(8 \%)$ & $7(9 \%)$ & 0.879 \\
\hline Peripheral vascular disease & $2(3 \%)$ & $2(2 \%)$ & 0.670 \\
\hline Chronic obstructive pulmonary disease & $5(7 \%)$ & $4(5 \%)$ & 0.901 \\
\hline EuroScore II & $1.82 \pm 0.32$ & $1.85 \pm 0.27$ & 0.534 \\
\hline $\begin{array}{l}\text { Echocardiographic data } \\
\text { LVEDD }(\mathrm{mm}) \\
\text { LVESD }(\mathrm{mm}) \\
\text { LAD }(\mathrm{mm}) \\
\text { EF\% } \\
\text { Left atrial thrombus }\end{array}$ & $\begin{array}{l}62.5 \pm 3 \\
39.7 \pm 6 \\
55.1 \pm 4 \\
52.3 \pm 7 \\
4(5 \%)\end{array}$ & $\begin{array}{l}63.1 \pm 3 \\
38.2 \pm 5 \\
54.2 \pm 3 \\
51.2 \pm 6 \\
5(6 \%)\end{array}$ & $\begin{array}{l}0.223 \\
0.097 \\
0.119 \\
0.302 \\
0.901\end{array}$ \\
\hline
\end{tabular}

Abbreviations: EF, ejection fraction; LVEDD, left ventricular end-diastolic diameter; LVESD, left ventricular end-systolic diameter; LAD, left atrial diameter; NYHA, New York Heath Association.

minimally invasively through upper partial sternotomy, while the rest (186 cases) were done conventionally through full median sternotomy. The choice between the conventional and minimally invasive approaches was according to the patient risks as well as surgeon's confidence and preference. To compare the outcomes of both the conventional and minimally invasive approaches in patients receiving concomitant aortic and mitral valve surgeries during this period, a matched conventional group (group B) was created including 78 cases to be compared with the minimally invasive group (group A) including the 72 patients. Matching of group $B$ to group $A$ was done using propensity scores according to 17 preoperative patient characteristics (-Table $\mathbf{1}$ ). Our study was approved by the institutional ethical committee and due to its retrospective nature patient consent for enrollment in the study was waived.

\section{Exclusion Criteria}

No patients operated upon for subsequent times (redo cases) or due to endocarditis were included in the study. In addition, patients underwent cardiac procedures other than mitral and aortic valve surgeries were excluded.

\section{Definitions}

Preoperative renal impairment was defined as serum creatinine $>1.5 \mathrm{mg} / \mathrm{dL}$. Postoperative pain was assessed by asking the patients to grade their pain over a scale of 0 to 10 on the 1 st postoperative day after extubation as well as on the 3rd postoperative day. Operative mortality was defined as any death, regardless of the cause, occurring within 30 days after surgery in or out of the hospital. Patients were followed up through outpatient clinic visits as well as telephone questionnaires.

\section{Surgical Techniques}

The anesthetic protocol as well as the patient position is the same in all cases regardless of the surgical approach. In cases done through upper partial sternotomy, a skin incision of $\sim 7$ to $8 \mathrm{~cm}$ is done in the midline starting $1 \mathrm{~cm}$ below the suprasternal notch and ending opposite the 3rd intercostal space. An upper inverted T-shaped partial sternotomy is then performed using the oscillating saw. Now the pericardium is opened in the midline and suspended. After full heparinization, a double-stage venous cannula is placed into the right femoral vein percutaneously or through a small incision under transesophageal echocardiographic (TEE) guidance so that its tip lies in the superior vena cava and then an arterial cannula is inserted into the ascending aorta through the partial sternotomy incision before establishing the cardiopulmonary bypass (CPB). Subsequently, the aorta is crossclamped and cold blood cardioplegia is delivered into the aortic root or coronary ostia (in case of severe aortic regurgitation). The dome of the left atrium is opened between the 


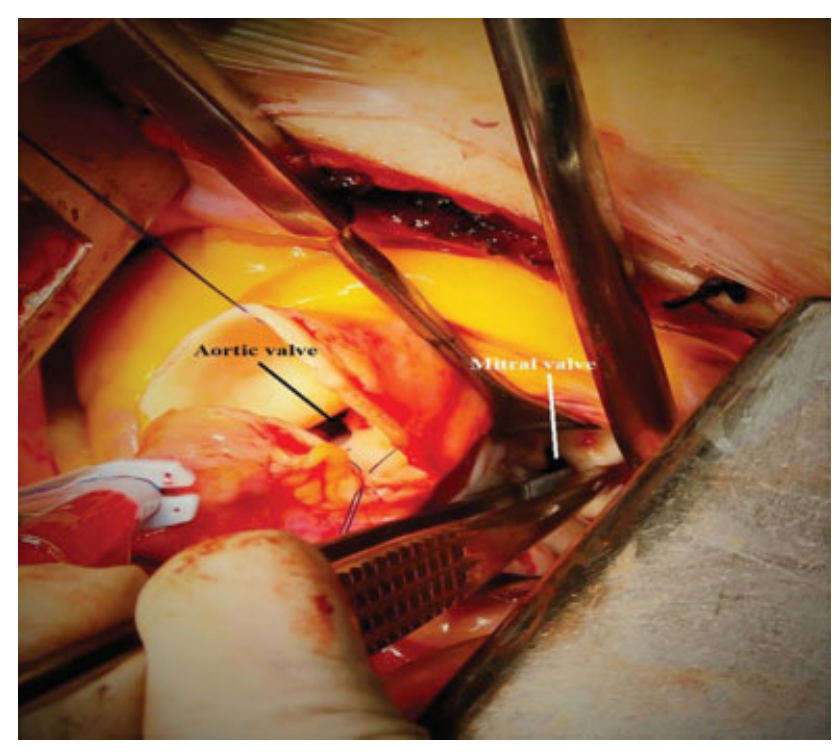

Fig. 1 Intraoperative photo showing the aortic valve through the aortotomy incision as well as the mitral valve through the opened dome of the left atrium via the upper mini-sternotomy approach.

junction of the left atrial roof with the superior vena cava and the ascending aorta in the direction of the left superior pulmonary vein to avoid injury of the sinoatrial nodal (SAN) artery. A small hand-held retractor is used to facilitate exposure of the mitral valve and a small vent is put into the left atrium to achieve a bloodless field. The mitral valve pathology is dealt with first by either repair or replacement and then the aortic valve is replaced through a transverse aortotomy. Finally, the aortotomy is closed in two layers followed by closure of the left atrial dome in one layer before deairing and declamping (-Fig. $\mathbf{1}$ ).

In conventional cases, after the full median sternotomy and full heparinization, aortobicaval cannulation is performed and CPB is established. Cardioplegia is achieved via cold blood delivered into the aortic root or coronary ostia (in case of severe aortic regurgitation). The pathological aortic valve is now excised through a transverse aortotomy and then the mitral pathology is dealt with through left atriotomy. Finally, the aortic valve is replaced and both the aortotomy and left atriotomy incisions are closed.

\section{Statistical Analysis}

Data were collected from medical records and patient registries and then coded to be entered into the SPSS (Statistical Package for the Social Sciences) version 22. Quantitative data were presented using the mean \pm standard deviation, while categorical data were presented as frequencies (counts) and relative frequencies (percentages). The means of continuous variables were compared between the two groups by the Student's $t$-test, while the rates and proportions were compared by the Chi-square or Fisher's exact tests. The propensity score matching between the groups was achieved by multiple logistic regression analysis based on 17 preoperative patient characteristics with creation of a propensity model to determine patient pairs for comparison. A $p$-value $<0.05$ was considered significant. Kaplan-Meier curves were used to determine survival.

\section{Results}

\section{Preoperative Data}

The mean age was $52 \pm 8$ years in group $A$ and $53 \pm 7$ years in group B. Males represented (42\%) in group A and (49\%) in group B. All cases in both groups were in New Heart Association classes II and III at the time of surgery. -Table 1 summarizes the preoperative patient characteristics in both groups with no statistically significant differences among the two study groups.

\section{Operative Data}

The mean cross-clamp time, CPB time, and total operative time were slightly longer in the group A than in group B but showed no statistically significant differences ( $p$-values are $0.291,0.071$, and 0.061 , respectively). All cases in both groups underwent aortic valve replacement. Concomitant mitral valve replacement was performed in 54 cases (75\%) of group $A$ and in 52 cases (67\%) of group B, while mitral valve repair was undertaken in 15 cases (21\%) of group $A$ and in 20 cases $(25 \%)$ of group B. Mitral valve repair in both groups was done by using rigid annuloplasty ring (St Jude Medical, St Paul, Minnesota, United States) in case of secondary mitral regurgitation with dilated annulus as well as artificial chordae and rigid annuloplasty ring in case of leaflet

Table 2 Summary of operative data in both study groups

\begin{tabular}{|l|l|l|l|}
\hline Operative data & Group A (72) & Group B (78) & $p$-Value \\
\hline Cross-clamp time (minutes) & $105 \pm 15$ & $103 \pm 7$ & 0.291 \\
\hline CPB time (minutes) & $135 \pm 12$ & $132 \pm 8$ & 0.071 \\
\hline Total operative time (minutes) & $179 \pm 7$ & $177 \pm 6$ & 0.061 \\
\hline $\begin{array}{l}\text { Aortic valve prosthesis } \\
\text { Mechanical } \\
\text { Biological }\end{array}$ & $69(96 \%)$ & $72(92 \%)$ & 0.572 \\
\hline $\begin{array}{l}\text { Mitral valve prosthesis } \\
\text { Mechanical } \\
\text { Biological }\end{array}$ & $3(4 \%)$ & $6(8 \%)$ & \\
\hline Mitral valve repair & $54(75 \%)$ & $52(67 \%)$ & 0.504 \\
\hline
\end{tabular}

Abbreviation: CPB, cardiopulmonary bypass. 
Table 3 Summary of postoperative data in both groups

\begin{tabular}{|l|l|l|l|}
\hline Postoperative data & Group A (72) & Group B (78) & $p$-Value \\
\hline Mechanical ventilation (hours) & $4.3 \pm 1.2$ & $6.1 \pm 0.8$ & 0.001 \\
\hline Duration of inotropic support (hours) & $12.1 \pm 2.5$ & $11.9 \pm 2.6$ & 0.632 \\
\hline Chest tube drainage (cm ${ }^{3}$ ) & $250 \pm 160$ & $320 \pm 180$ & 0.013 \\
\hline Need for blood transfusion (units) & $1.3 \pm 0.8$ & $1.8 \pm 0.9$ & 0.005 \\
\hline ICU stay (days) & $2.7 \pm 1.3$ & $2.5 \pm 0.9$ & 0.272 \\
\hline Hospital stay (days) & $8.1 \pm 1.8$ & $8.3 \pm 1.5$ & 0.459 \\
\hline Postoperative complications & & & \\
Re-exploration for bleeding & $1(1 \%)$ & $3(4 \%)$ & 0.670 \\
Cerebrovascular stroke & $1(1 \%)$ & $1(1 \%)$ & 0.512 \\
Renal failure necessitating dialysis & $1(1 \%)$ & $2(1 \%)$ & 0.944 \\
Heart block requiring PPM & $2(3 \%)$ & $1(1 \%)$ & 0.944 \\
Deep sternal wound infection & $1(1 \%)$ & $2(1 \%)$ & 0.944 \\
\hline Postoperative pain (mean of a scale 0-10) & & & \\
Day 1 & $5.7 \pm 1.2$ & $5.9 \pm 0.7$ & 0.210 \\
Day 3 & $3.2 \pm 0.9$ & $3.4 \pm 0.6$ & 0.109 \\
\hline Operative mortality & $1(1 \%)$ & $1(1 \%)$ & 0.512 \\
\hline
\end{tabular}

Abbreviations: ICU, intensive care unit; PPM, permanent pacemaker.

prolapse. - Table 2 summarizes operative data in both groups. No sutureless valve was used in our study population. No conversion to full median sternotomy took place in group A.

\section{Postoperative Data}

The mean duration of mechanical ventilation was significantly shorter in group A ( $4.3 \pm 1.2$ hours) than in group B $(6.1 \pm 0.8$ hours $)$ with a $p$-value of 0.001 . In addition, the amount of chest tube drainage and the need for blood transfusion units were significantly less in group A $\left(250 \pm 160 \mathrm{~cm}^{3}\right.$ and $1.3 \pm 0.8$ units, respectively) when compared with group B $\left(320 \pm 180 \mathrm{~cm}^{3}\right.$ and $1.8 \pm 0.9$ units, respectively) with $p$-values of 0.013 and 0.005 , respectively. It is worth noting that 22 cases (30.5\%) of group A developed nodal rhythm immediately after removal of the aortic crossclamp and only 5 cases (6\%) of group B showed this rhythm after declamping ( $p$-value $=0.003$ ). However, all cases with nodal rhythm regained sinus rhythm on the 2nd or 3rd day. Only one operative mortality occurred in each group due to profound low cardiac output syndrome resistant to maximal inotropic support and intra-aortic balloon pulsations. Other postoperative data were similar in both groups with no statistically significant differences. - Table 3 demonstrates postoperative results. Postoperative echocardiography showed well-seated well-functioning prostheses in all cases included in the study with no abnormal gradients or significant paravalvular leaks. In cases, received mitral valve repair in both groups no regurgitation more than Grade I was detected postoperatively.

\section{Follow-Up Data}

Follow-up data are available for 69 cases in group A (96\%) and for 75 cases in group B (92\%) over a follow-up period of $38.3 \pm 13.2$ months. During this period, one mortality due to infective endocarditis occurred in group A and one mortality in group B due to massive cerebral hemorrhage as a sequel of anticoagulation with no significant difference ( $p$ value $=0.512$ ). - Fig. 2 shows Kaplan-Meier curve for survival in both groups.

\section{Discussion}

Advantages of different minimally invasive approaches through smaller or alternative chest wall incisions over full median sternotomy are now well recognized including less postoperative bleeding or need for blood transfusion, shorter intensive care unit (ICU) and hospital stays, smaller more cosmetic wounds as well as faster recovery with earlier return to normal activity. These techniques should be as

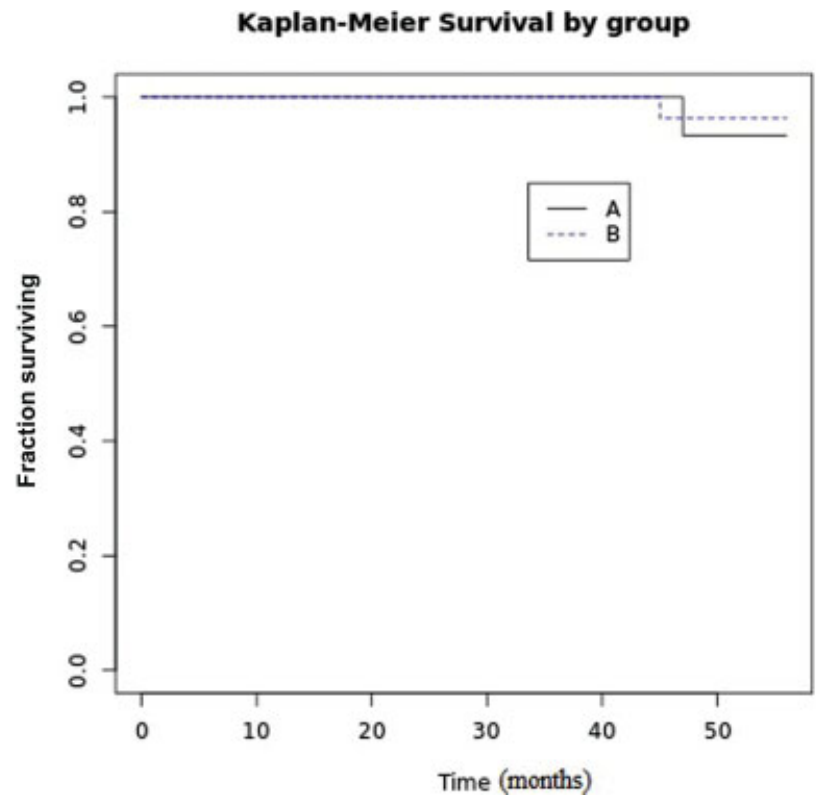

Fig. 2 Kaplan-Meier survival curve in groups A and B. 
safe and effective as the standard approach and allow both valve replacement and repair. ${ }^{4}$

Several minimally invasive approaches are used for isolated mitral valve surgery like lower or upper mini-sternotomy, right parasternal incision, and right mini-thoracotomy ${ }^{5}$ as well as for isolated aortic valve surgery like upper ministernotomy and right mini-thoracotomy. ${ }^{6}$

Nevertheless, since it is the fate of cardiac surgeons to compete with less invasive interventional procedures and try steadily to push their limits in minimally invasive surgical techniques; therefore, surgeons are now asked to find a minimally invasive technique to deal with both aortic and mitral valve pathologies concomitantly through a minimally invasive approach. These two valves can be approached minimally invasively through several incisions; most commonly the upper partial sternotomy and right mini-thoracotomy $^{7}$ as well as less commonly the right parasternal incision. ${ }^{8}$ However, right mini-thoracotomy provides complete preservation of the entire sternum avoiding all the sternotomy complications with superior cosmetic results when compared with the partial sternotomy and right parasternal approaches. ${ }^{9}$ Yet right mini-thoracotomy requires the use of special instruments with nontraditional exposure of the aortic valve resulting in significant increase of the cross-clamp and CPB times especially at the beginning of the learning curve. In addition, cases suitable for aortic valve surgery via right mini-thoracotomy should be carefully selected according to certain computer tomographic scan criteria. ${ }^{10}$ Also implantation of the aortic valve through right mini-thoracotomy is to some extent dependent on sutureless valves, the deployment of which could be challenging in the presence of mitral prosthesis with a narrow aortomitral continuity. ${ }^{11,12}$ The right parasternal incision entails division of the 3th and 4th costal cartilages and therefore it appears more destructive in nature than other approaches. It has been nowadays abandoned by most cardiac centers. ${ }^{8}$ On the other hand, the partial sternotomy approach gives a near traditional exposure of the aortic valve with the use of ordinary instruments and without the need of sutureless valves that are relatively coasty. Therefore, the aortic crossclamp and the СРВ times are not significantly prolonged in comparison with the conventional approach. ${ }^{13}$ In addition, partial sternotomy does not require the computed tomographic criteria needed for mini-thoracotomy and can be easily and rapidly converted to the full median sternotomy incision in case of complications. ${ }^{14}$ Also, it allows direct cannulation of the ascending aorta with physiologic antegrade blood flow during the CPB. ${ }^{15}$ Since we were familiar with exposure of the mitral valve through the dome of the left atrium earlier through full median sternotomy and later on through upper partial sternotomy, we have chosen to perform combined aortic and mitral valve surgery via upper partial sternotomy with approaching the mitral valve through the dome of the left atrium. Although exposure of the mitral valve through the left atrial dome is not widely utilized by cardiac surgeons since it has been described by Meyer et al in 1965, yet this approach has the advantages of being simple, rapid, and easy for deairing. In addition, it allows direct visualization of the mitral valve as well as the suture line at the end of surgery without the need for extensive dissection of the heart. ${ }^{16}$ Also, it permits a smaller partial sternotomy incision till the 3rd when dealing with the mitral valve in comparison with the superior trans-septal approach frequently used by centers that perform combined aortic and mitral valve surgeries through upper partial sternotomy. ${ }^{8}$ Even with the appearance of series reporting minimally invasive triple valve surgery, dealing with the tricuspid valve as well, through right mini-thoracotomy like that of Faerber et al, ${ }^{17}$ partial sternotomy allows also exposing the tricuspid valve through the right atrium after placing a separate cannula in the superior vena cava or using a twostage femoral venous cannula with its upper holes positioned in the superior vena cava and its lower holes positioned in the inferior vena cava under TEE guidance.

In our series, the duration of postoperative mechanical ventilation was significantly shorter in group A in comparison with group $B$ that may be attributed to the partial preservation of the sternum and thus chest wall integrity with better postoperative respiratory mechanics. ${ }^{17}$ However, the shorter mechanical ventilation time was not reflected as a significantly shorter ICU stay and thus hospital stay in group A than in the group B due to the significantly larger number of patients in group A having nodal rhythm after surgery ( $p$-value $=0.003$ ). This higher incidence of temporary postoperative nodal rhythm is attributed to the incision across the dome of the left atrium that might injure some branches of the SAN artery especially when having an abnormal course or some anterior internodal conduction pathways. ${ }^{16,18}$ However, a complete injury of the SAN artery could be voided by directing the incision toward the left superior pulmonary vein and thus persistent nodal rhythm was not encountered in our series and all cases regained sinus rhythm on the 2 nd or 3 rd postoperative days. ${ }^{16}$ Also, the postoperative blood loss and need for blood transfusion were significantly less in group A than in group B that is due to the smaller incisional area, a consistent benefit of minimally invasive approaches. ${ }^{19}$ On the contrary, operative time parameters such as cross-clamp and CPB times as well as postoperative outcomes including postoperative complications, postoperative pain, and operative mortality were not statistically significantly different between group A and group B.

In addition, our minimally invasive approach did not preclude the ability to repair the mitral valve when repair was considered to be feasible. Nevertheless, since rheumatic heart disease is the main pathological valve affection in our community; therefore, valve repair in general is not possible in many cases of our series whether conventionally or minimally invasively operated.

Thus, we believe that combined aortic and mitral valve surgery through upper partial sternotomy with approaching the mitral valve through the dome of the left atrium represents a novel, simple, and safe option for minimally invasive double valve surgery especially when other approaches such as right mini-thoracotomy due to anatomical or financial obstacles are considered inapplicable. 


\section{Limitations}

Our study carries some limitations in the form of the retrospective nature and single-center experience. In addition, owing to the relative rarity of cases requiring concomitant aortic and mitral valve surgeries in comparison with isolated valve cases and difficulty in matching conventional and minimally invasive double aortic and mitral valve cases, the population of the study was not large. This might have masked some significant differences between both study groups. Therefore, more future studies with larger cohorts and multiple minimally approaches may be needed.

\section{Conclusion}

Combined aortic and mitral valve surgery through upper partial sternotomy with approaching the mitral valve through the dome of the left atrium is safe and effective with the advantages of less postoperative blood loss, need for blood transfusion, and mechanical ventilation time compared with conventional aortic and mitral valve surgeries through full median sternotomy.

Funding

There are no funders to report for this submission.

Conflict of Interest

None.

\section{References}

1 Goldstone AB, Joseph Woo Y. Minimally invasive surgical treatment of valvular heart disease. Semin Thorac Cardiovasc Surg 2014;26(01):36-43

2 Lio A, Miceli A, Ferrarini M, Glauber M. Minimally invasive approach for aortic and mitral valve surgery. Eur J Cardiothorac Surg 2016;50(06):1204-1205

3 Lamelas J, Mawad M, Williams R, Weiss UK, Zhang Q LaPietra A. Isolated and concomitant minimally invasive minithoracotomy aortic valve surgery. J Thorac Cardiovasc Surg 2018;155(03): 926-936.e2

4 Alkady H. Minimally invasive mitral valve surgery: an update. Int J Cardiovasc Thoracic Surg 2017;3:32-40

5 Gammie JS, Zhao Y, Peterson ED, O'Brien SM, Rankin JS, Griffith BPJ. J. Maxwell Chamberlain Memorial Paper for adult cardiac surgery. Less-invasive mitral valve operations: trends and out- comes from the Society of Thoracic Surgeons Adult Cardiac Surgery Database. Ann Thorac Surg 2010;90(05):1401-1408, 1410.e1, discussion 1408-1410

6 Glauber M, Ferrarini M, Miceli A. Minimally invasive aortic valve surgery: state of the art and future directions. Ann Cardiothorac Surg 2015;4(01):26-32

7 Vola M, Fuzellier J-F. Extending minimally invasive approaches to concomitant aortic and mitral valve surgery: are we ready? Eur J Cardiothorac Surg 2016;50(06):1206-1207

8 Atik FA, Svensson LG, Blackstone EH, Gillinov AM, Rajeswaran J, Lytle BW. Less invasive versus conventional double-valve surgery: a propensity-matched comparison. J Thorac Cardiovasc Surg 2011;141(06):1461-8.e4

9 Lamelas J. Minimally invasive concomitant aortic and mitral valve surgery: the "Miami Method". Ann Cardiothorac Surg 2015;4(01): 33-37

10 Zhao D, Wei L, Zhu S, et al. Combined mitral and aortic valve procedure via right mini-thoracotomy versus full median sternotomy. Int Heart J 2019;60(02):336-344

11 Minh TH, Mazine A, Bouhout I, et al. Expanding the indication for sutureless aortic valve replacement to patients with mitral disease. J Thorac Cardiovasc Surg 2014;148(04):1354-1359

12 Gilmanov D, Miceli A, Bevilacqua S, et al. Sutureless implantation of the perceval $s$ aortic valve prosthesis through right anterior minithoracotomy. Ann Thorac Surg 2013;96(06):2101-2108

13 Svensson LG. Minimally invasive surgery with a partial sternotomy "J" approach. Semin Thorac Cardiovasc Surg 2007;19(04): 299-303

14 Sun H-S, Ma W-G, Xu J-P, Sun L-Z, Lu F, Zhu X-D. Minimal access heart surgery via lower ministernotomy: experience in 460 cases. Asian Cardiovasc Thorac Ann 2006;14(02):109-113

15 Modi P, Chitwood WR Jr. Retrograde femoral arterial perfusion and stroke risk during minimally invasive mitral valve surgery: is there cause for concern? Ann Cardiothorac Surg 2013;2(06): E1

16 Légaré JF, Buth KJ, Arora RC, Murphy DA, Sullivan JA, Hirsch GM. The dome of the left atrium: an alternative approach for mitral valve repair. Eur J Cardiothorac Surg 2003;23(03):272-276

17 Faerber G, Tkebuchava S, Scherag A, et al. Right mini-thoracotomy for aortic plus mitral with or without tricuspid valve surgery. Thorac Cardiovasc Surg 2020

18 Totaro P, Carlini S, Pozzi M, et al. Minimally invasive approach for complex cardiac surgery procedures. Ann Thorac Surg 2009;88 (02):462-466, discussion 467

19 Shin H, Yozu R, Higashi S, Kawada S. Sinus node function after mitral valve surgery using the superior septal approach. Ann Thorac Surg 2001;71(02):587-590

20 Mihaljevic T, Cohn LH, Unic D, Aranki SF, Couper GS, Byrne JG. One thousand minimally invasive valve operations: early and late results. Ann Surg 2004;240(03):529-534, discussion 534 